\title{
Clear cell carcinomas of the ovary: a mono- institutional study of 73 cases in China with an analysis of the prognostic significance of clinicopathological parameters and IMP3 expression
}

\author{
Rui $\mathrm{Bi}^{1,2}$, Xuxia Shen ${ }^{1,2}$, Weiwei Zhang ${ }^{3}$, Yufan Cheng ${ }^{1,2}$, Zheng Feng ${ }^{2,4}, \mathrm{Xu}_{\mathrm{Cai}}{ }^{1,2}$ and Wentao Yang ${ }^{1,2^{*}}$
}

\begin{abstract}
Background: Ovarian clear cell carcinoma (CCC) is an uncommon subtype of ovarian epithelial tumor. The prognostic significance of its clinicopathological parameters is discordant, with the exception of stage as the adverse prognostic factor. The present study aimed to evaluate the prognostic significance of its clinicopathological characteristics and the expression of IMP3 (Insulin-like growth factor-II mRNA-binding protein 3, IMP3 or IGF2BP3) in Chinese patients with primary pure CCC.
\end{abstract}

Methods: We collected clinicopathological data from 73 cases with a minimum of 5 years of follow-up and evaluated the expression of IMP3 by immunohistochemistry.

Results: In total, $49.3 \%$ of the patients were in stage I. Advanced stages were closely related to poor prognosis of disease-free survival (DFS) and overall survival (OS) $(P<0.005)$. Patients with CCC coexisting with endometriosis tended to be younger and to have unilateral involvement but did not exhibit differences in prognosis compared with patients with CCC without endometriosis. Other histological features such as growth pattern, mitosis, and necrosis did not have prognostic significance. IMP3 was positive in $63 \%$ of patients (46 of 73 cases); Thus, positive expression of IMP3 is an adverse prognostic marker in terms of OS $(P=0.012)$, even in stage I patients $(P=0.038)$.

Conclusions: The present study demonstrates that IMP3 expression is a prognostic marker, with the exception of stage. IMP3 represents a biomarker of unfavorable prognosis even in stage I patients.

Keywords: Clear cell carcinoma, Prognosis, Stage, Endometriosis, IMP3

\section{Background}

The prevalence of ovarian clear cell carcinoma (CCC), which has significant geographic differences, accounts for $5-25 \%$ of cases in various countries [1, 2]. Most of CCC in stage I [3] associated with endometriosis [4] has a poor response to platinum-based regimens, which results in an unfavorable prognosis, particularly for advanced stages $[3,5,6]$. The various morphologies of

\footnotetext{
*Correspondence: yangwt2000@163.com

'Department of Pathology, Fudan University Shanghai Cancer Center, Shanghai 200032, China

${ }^{2}$ Department of Oncology, Shanghai Medical College, Fudan University, Shanghai 200032, China

Full list of author information is available at the end of the article
}

CCC result in misclassification, which further affects the assessment of morbidity and prognostic factors. A grading system based on CCC growth pattern correlates with survival in ovarian CCC [7]. However, this relationship has not been further confirmed, and the impact of the histopathological characteristics on prognosis has been disputed.

Insulin-like growth factor-II mRNA-binding protein 3 (IMP3 or IGF2BP3), a member of the IMP family, is highly expressed in embryo. This protein is involved in the binding, transport and stability of the embryonic isoforms of the IGF-II gene. IMP3 is considered as an oncofetal protein and is related to tumor metastasis. 
This protein is often found to be overexpressed in many types of tumors, such as gastric cancer, colorectal cancer, liver cancer, and pancreatic cancer, where it acts as an independent prognostic factor [8-11]. However, few studies have examined the role of IMP3 in gynecologic tumors, such as in ovarian CCC, endometrial CCC and cervical squamous carcinomas [12-14]. IMP3 expression in ovarian CCC was reported in a previous study; however, subsequent studies with small sample size have not confirmed the same results $[12,15]$. Therefore, the significance of IMP3 expression in ovarian cancer, particularly in CCC, requires further analysis.

Few studies of primary pure ovarian CCC have been examined in Chinese patients and the lack of effective prognostic indicators in addition to staging. Therefore, reviewing and understanding the characteristics of CCC and assessing IMP3 expression as a prognostic parameter are of great importance.

\section{Methods}

\section{Patients and clinicopathological characteristics}

The present study was approved by the Ethical Review Committee of Fudan University Shanghai Cancer Center. Data were collected from 73 patients with a primary diagnosis of pure ovarian CCC who underwent their first operation at Fudan Cancer Center between 1999 and 2009 and who had a minimum of 5 years of follow-up. Hematoxylin-eosin (HE)-stained sections were reviewed by three gynecological pathologists. The patients underwent total abdominal hysterectomy, bilateral salpingo-oophorectomy, omentectomy, and appendectomy simultaneously or asynchronously. The patients were then treated with platinum-based postoperative chemotherapy. Staging was determined according to the 2014 FIGO new ovarian, tubal, peritoneal tumor staging guidelines [16].

Histological morphology was estimated approximately according to the summary of DeLair et al. [17] for the determination of tumor growth pattern (tubulocystic, solid, or papillary), cell type (clear cell, oxyphil cell, hobnail cell or columnar cell), mitotic index (10/HPF), stroma (hyalinized, myxoid, fibroblastic), and necrosis. We also evaluated the presence of endometriosis (ovarian and/or extra-ovarian) in the specimens.

\section{Immunohistochemistry}

IMP3 expression was evaluated by immunohistochemistry using the EnVision method [15]. Briefly, sections $(4 \mu \mathrm{m})$ were deparaffinized and treated with $0.3 \%$ hydrogen peroxide, boiled in citrate buffer ( $\mathrm{pH}$ 6.0) for $15 \mathrm{~min}$, and cooled at room temperature. Sections were incubated with a primary IMP3 antibody (Clone 69.1, dilution 1:200, Dako Glostrup, Denmark) at $4{ }^{\circ} \mathrm{C}$ overnight, rinsed in PBS, and then incubated for $40 \mathrm{~min}$ with biotinylated secondary antibody. Sections were stained in DAB (Dako, Glostrup, Denmark), rinsed three times in PBS, and then counterstained with hematoxylin. Incubation in PBS buffer in lieu of primary antibody was used as a negative control, and IMP3 expression in the germinal center of the lymph node served as a positive control. We defined positive IMP3 staining as convincing cytoplasmic expression in more than $10 \%$ of tumor cells [18]. The positive staining intensity was recorded as weak, moderate, or strong.

\section{Follow-up}

The patients were followed up until March 31, 2014. Overall survival (OS) was defined as the time from operation to either death or the last follow-up. Disease-free survival (DFS) was defined as the interval from operation to disease recurrence or the last follow-up. We defined disease recurrence as a consistent elevation of CA125, or observation of tumor by clincial examination including physical examination and imaging studies [19].

\section{Statistical analyses}

The chi-square test and Fisher's exact test were used to evaluate the association between IMP3 expression and multiple clinicopathological parameters. Survival analysis was determined using Kaplan-Meier univariate analysis. Differences in survival curves were compared with the log-rank test. $P$ values $<0.05$ were considered significant. For statistical analyses, SPSS software version 19.0 (IBM SPSS Statistics 19) was used.

\section{Results}

\section{Clinicopathological characteristics}

The ages of the 73 patients ranged from 19 to 80 years old (mean, 53.63 years; median, 54 years). Macroscopically, the tumor size ranged from 2 to $27 \mathrm{~cm}$ (mean, $10.45 \mathrm{~cm}$ ). Unilateral tumors were the most frequent, occurring in 58 cases $(79.5 \%)$, while bilateral tumors occurred in 15 cases (20.5\%). The serum level of CA125 was above normal in the 56 preoperative cases $(47 / 56$, $83.9 \%$ ). Ascites were present in $48.5 \%$ of patients (33/ 68 ) and absent in $51.5 \%$ (35 cases) of patients in the recorded data. The percentages of cases at each FIGO stage were as follows: stage I, $49.3 \%$ (36 cases); stage II, $15.1 \%$ (11 cases); stage III, $24.7 \%$ (18 cases) and stage IV, $11 \%$ (8 cases). Follow-up information was obtained from 69 patients. The OS of patients ranged from 0.7 to 173.8 months (mean, $61.2 \mathrm{~m}$; median, $59 \mathrm{~m}$ ), and the DFS ranged from 0.7 to 173.8 months (mean, $53.2 \mathrm{~m}$; median, $38.2 \mathrm{~m}$ ). The 5 -year survival rate varied among stages as follows: stage I (26/33, $78.8 \%$ of cases), stage II (5/11, $45.5 \%$ of cases), stage III (5/18, $27.8 \%$ of cases), and stage IV $(0 / 6,0 \%$ of cases $)(P<0.001)$. 
Histopathological features were summarized in Table 1. Basically, ovarian clear cell carcinomas showed a variable admixture of papillary, tubulocystic and solid growth pattern. A variable papillary component was present in $82.2 \%$ of cases (60 of 73). Pure papillary pattern, tubulocystic pattern and solid pattern were observed in $34.2 \%$ (25/73), $6.8 \%$ (5/73) and $2.7 \%$ (2/73) cases respectively. Mixed papillary and tubulocystic pattern were present in $27.4 \%(20 / 73)$ cases. Mixed tubulocystic and solid pattern, mixed papillary and solid were observed in $8.2 \%(6 / 73)$ and $8.2 \%(6 / 73)$ respectively. A mixed

Table 1 Morphological characteristics in 73 cases of ovarian clear cell carcinoma

\begin{tabular}{|c|c|}
\hline Morphology & Cases (\%) \\
\hline \multicolumn{2}{|l|}{ Growth pattern } \\
\hline Tubulocystic & $5(6.8)$ \\
\hline Solid & $2(2.7)$ \\
\hline Tubulocystic/Solid & $6(8.2)$ \\
\hline Papillary & $25(34.2)$ \\
\hline Papillary/Tubulocystic & $20(27.4)$ \\
\hline Papillary/Solid & $6(8.2)$ \\
\hline Tubulocystic/Solid/Papillary & $9(12.3)$ \\
\hline at least focal papillary componen & $60(82.2)$ \\
\hline \multicolumn{2}{|l|}{ Cell type } \\
\hline Clear cell & $11(15.1)$ \\
\hline Oxyphil cell & $5(6.8)$ \\
\hline Mixed with Clear and oxyphil cell & $57(78.1)$ \\
\hline Hobnailing & $41(56.2)$ \\
\hline Columnar cell & $2(2.7)$ \\
\hline \multicolumn{2}{|l|}{ Mitotic figures (/10 HPF) } \\
\hline $0-9$ & $65(89.0)$ \\
\hline $10-19$ & $8(11.0)$ \\
\hline \multicolumn{2}{|l|}{ Stroma } \\
\hline Hyalinized only & $4(5.5)$ \\
\hline Myxoid only & $1(1.4)$ \\
\hline Fibroblastic only & $23(31.5)$ \\
\hline Fibroblastic/Hyalinized & $20(27.4)$ \\
\hline Fibroblastic/Myxoid & $4(5.5)$ \\
\hline Hyalinized/Myxoid & $1(1.4)$ \\
\hline Fibroblastic/Hyalinized/Myxoid & $20(27.4)$ \\
\hline \multicolumn{2}{|l|}{ Other miscellaneous characteristics } \\
\hline Focal or patchy necrosis & $29(39.7)$ \\
\hline Targetoid bodies & $3(4.1)$ \\
\hline Psammoma bodies & $8(11.0)$ \\
\hline Mucin secretion & $8(11.0)$ \\
\hline Open tumor rings & $6(8.2)$ \\
\hline Nuclear pseudoinclusions & $6(8.2)$ \\
\hline
\end{tabular}

pattern of papillary, tubulocystic and solid were present in $12.3 \%$ (9/73) cases. Ovarian clear cell carcinomas were composed by variable proportions of clear cells, oxyphilic cells, hobnail cells and colunmar cells. Hobnail cells were present in $56.2 \%$ (41/73) of all cases. A mixture of clear cells and oxyphilic cells was present in $78.1 \%(57 / 73)$ cases, Pure clear cell type was observed in $15.1 \%(11 / 73)$ cases. $6.8 \%(5 / 73)$ cases composed of pure oxyphilic cell. Rare cases presented with columnar cells with subnuclear or supranuclear vacuoles (Fig. 1a). The mean mitotic index was 4.6/10 HPFs. Mitotic figures were 0-9/10 high-power fields (HPFs) in 65 cases (89 \%). The remaining cases had more than $10 / 10 \mathrm{HPF}$, with the highest of $17 / 10$ HPFs. Diversity was observed among the stromal changes, including fibrous, hyaline and myxoid stroma. Pure hyaline or myxoid stroma were observed in 4 cases $(5.5 \%)$ and 1 case (1.4\%) respectively. Focal or patchy necrosis was observed in $39.7 \%$ $(29 / 73)$ of the cases. Targetoid bodies (signet ring-like cells with eosinophil/basophil secretions, shown in Fig. 1b), psammoma bodies (Fig. 1c), and open tumor cell rings (rings of tumor cells without central stroma, Fig. 1d) were presented in some cases. Tubulocysts filled with mucinous secretions were observed in eight cases, one of which with severe expansile tubulocysts resembling thyroid follicles (Fig. 1e). Scattered nuclear pseudoinclusions were noted in 6 cases (Fig. 1f). Endometriosis was observed in the specimen in $23.3 \%$ (17 of 73) of the cases.

\section{Clinical parameters and survival (Table 2)}

Follow-up information was obtained for 69 patients, including 33 in stage I, 11 in stage II, 18 in stage III, and 7 in stage IV. The mean OS of each stage was as follows: I, 85.3 months; II, 57.15 months; III, 31.5 months; and IV, 30.1 months. Statistically significant differences in the mean OS were observed $(P<0.001)$. The mean DFS of each stage was as follows: I, 79.9 months; II, 45.4 months; III, 24 months; and IV, 14 months. The differences in the mean DFS were also significantly different $(P<0.001)$. The survival of patients with stage I disease resulted in a remarkably favorable prognosis compared with that of patients in stages II-IV; we then analyzed the data from the two groups in stages I and II-IV. The comparison of DFS and OS between the patients in stages $\mathrm{Ia} / \mathrm{Ib}$ and Ic showed no statistically significant differences $(P=0.440$ and $P=0.875$, respectively).

Moreover, patients with ovarian CCC coexisting with endometriosis were prone to develop unilateral tumors $(P=0.038)$, with a trend of occurrence in relatively younger patients (15 patients of $<60$-year-old group vs. 2 patients of $\geq 60$-year-old group, $P=0.062$ ). Other clinical parameters, such as age, tumor size, preoperative CA125 level, ascites, and endometriosis, exhibited no 

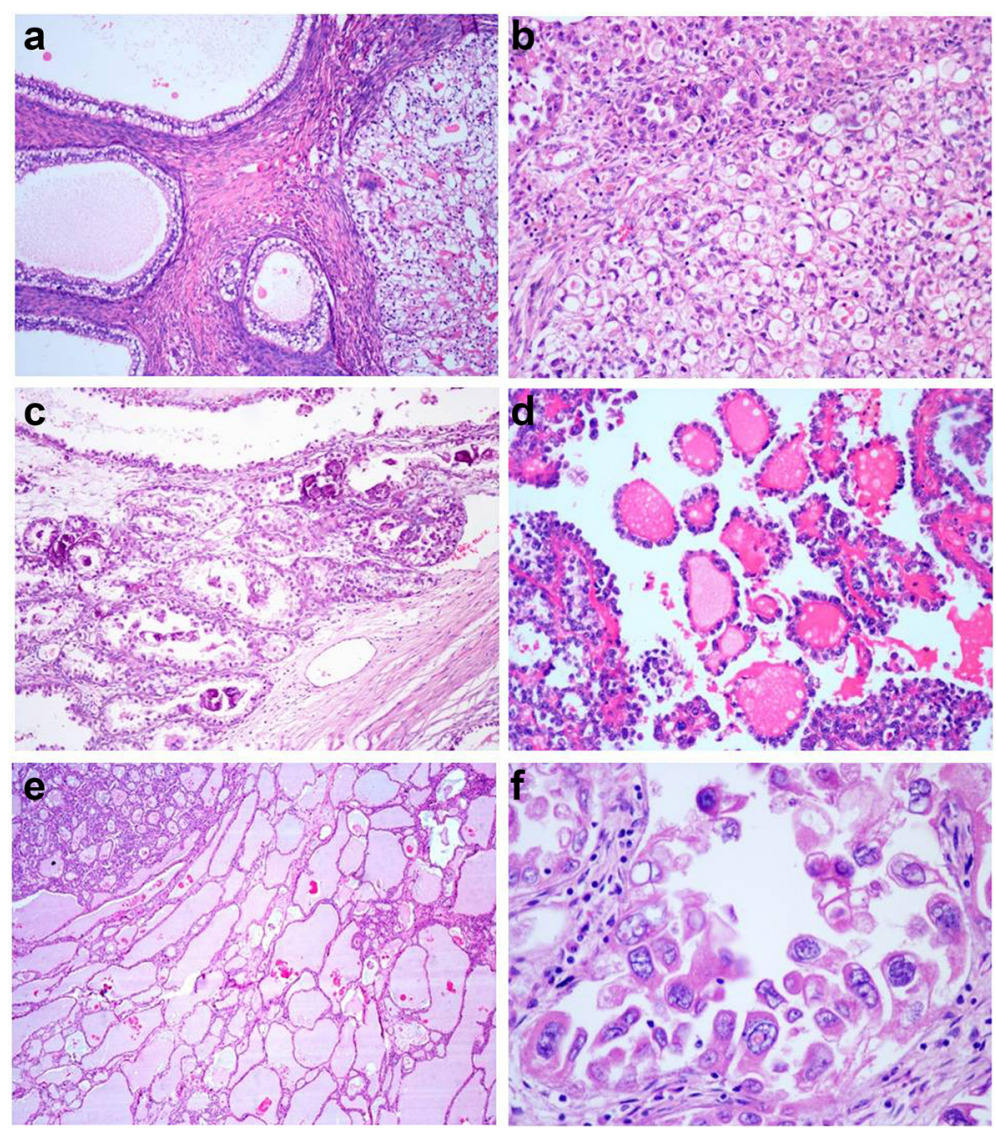

Fig. 1 a A solid nest is on the right, and the cystic morphology with columnar cells resembles an endometrial gland. b Targetoid bodies are signet ringlike cells contained with eosinophil/basophil secretions. Classic hobnail cells can be observed in the top left corner. c Scattered psammoma bodies. $\mathbf{d}$ Open tumor rings consist of a ring of tumor cells without a central fibrovascular stroma (A-D; original magnification, $\times 200$ ). e Extremely expansive tubulocystic morphology with mucinous secretions similar to a thyroid follicle (original magnification, $\times 40$ ). $\mathbf{f}$ Nuclear pseudoinclusions were observed with severe cell atypia, but mitotic figures were absent (original magnification, $\times 400$ )

significant difference in their association with DFS and OS between groups (Table 2).

\section{IMP3 immunohistochemical staining and survival}

Forty-six of the 73 cases (63\%) showed positive IMP3 expression (Fig. 2a and 2b), and the remaining 27 cases (37 \%) were IMP3 negative.

The rate of IMP3 expression was significantly higher in patients with an advanced stage (II-IV), with $73.0 \%$ positive cases (27 of 37), compared with the $52.8 \%$ of cases observed in stage I (19 of 36) $(P=0.046)$. The OS was significantly shorter in IMP3-positive patients than in those negative cases (55.8 months vs. 71.3 months, $P=0.012$, Fig. 3a), but no significant difference was observed for DFS $(P=0.175)$. Upon further stratification analysis of IMP3 expression in patients with stage I, the IMP3-positive cases (23-133.6 months, mean 76.0 months) had a shorter OS than did the IMP3negative cases (11.2-173 months, mean 96.5 months) $(P=0.038$, Fig. $3 b)$. None of the 17 IMP3-negative cases of stage I died. However, 4 of 19 IMP3-positive cases died from ovarian CCC metastasis, and their OS ranged from 23.0 to 76 months (mean 40.4 months). Nevertheless, the DFS did not differ significantly between IMP3positive and IMP3-negative cases $(P=0.557)$. However, no statistically significant differences in OS and DFS were observed in patients with stage II-IV CCC $(P=$ 0.892 and $P=0.840$, respectively).

\section{Discussion}

Compared with common serous carcinomas, ovarian CCC has distinct features such as poor prognosis and platinum drug resistance. A relatively high percentage of CCC cases are in stage I (31--60\%) [20-23], which is significantly higher than the percentage of patients who have serous carcinoma $(16.6-20 \%)[3,24]$. Stage I cases accounted for approximately 45.8-62.8 \% of Chinese CCC patients $[25,26]$. The percentage of pure CCC patients in stage I in the present study was $49.3 \%$ 
Table 2 The association of the clinical features and the expression of IMP3 with the prognosis of 73 patients with ovarian clear cell carcinoma

\begin{tabular}{|c|c|c|c|c|c|c|c|c|c|}
\hline & & \multirow{2}{*}{$\begin{array}{l}\text { DFS } \\
P\end{array}$} & \multirow{2}{*}{$\begin{array}{l}\text { OS } \\
P\end{array}$} & \multicolumn{3}{|c|}{ IMP3 expression } & \multicolumn{3}{|c|}{ Endometriosis } \\
\hline & & & & Positive & Negative & $P$ & Present & Absent & $P$ \\
\hline \multirow[t]{3}{*}{$\overline{\text { Age }}$} & & & & & & 0.097 & & & 0.071 \\
\hline & $\geq 60 y$ & 0.084 & 0.073 & 17 & 5 & & 2 & 19 & \\
\hline & $<60 y$ & & & 29 & 22 & & 15 & 36 & \\
\hline \multirow[t]{3}{*}{ Tumor size } & & & & & & 0.222 & & & 0.415 \\
\hline & $\geq 15 \mathrm{~cm}$ & 0.337 & 0.285 & 8 & 8 & & 5 & 11 & \\
\hline & $<15 \mathrm{~cm}$ & & & 38 & 19 & & 12 & 44 & \\
\hline \multirow[t]{3}{*}{ Lateral } & & & & & & 0.786 & & & 0.038 \\
\hline & Unilateral & / & / & 37 & 21 & & 40 & 17 & \\
\hline & Bilateral & & & 9 & 6 & & 15 & 0 & \\
\hline \multirow[t]{3}{*}{ CA125 } & & & & & & 0.115 & & & 0.375 \\
\hline & Above normal & 0.201 & 0.935 & 29 & 18 & & 10 & 34 & \\
\hline & Normal & & & 8 & 1 & & 3 & 5 & \\
\hline \multirow[t]{3}{*}{ Ascites } & & & & & & 0.347 & & & 0.521 \\
\hline & Present & 0.055 & 0.271 & 19 & 14 & & 9 & 7 & \\
\hline & Absent & & & 24 & 11 & & 24 & 27 & \\
\hline \multirow[t]{3}{*}{ Endometriosis } & & & & & & 0.352 & / & I & / \\
\hline & Present & 0.534 & 0.424 & 9 & 8 & & & & \\
\hline & Absent & & & 36 & 19 & & & & \\
\hline \multirow[t]{3}{*}{ Necrosis } & & & & & & 0.260 & & & 0.296 \\
\hline & Present & 0.377 & 0.499 & 16 & 13 & & 5 & 24 & \\
\hline & Absent & & & 30 & 14 & & 12 & 31 & \\
\hline \multirow[t]{3}{*}{ Papillary component } & & & & & & 0.188 & & & 0.631 \\
\hline & Present & 0.123 & 0.180 & 37 & 18 & & 12 & 42 & \\
\hline & Absent & & & 9 & 9 & & 5 & 13 & \\
\hline \multirow[t]{3}{*}{ Mitotic figures (/10 HPF) } & & & & & & 0.488 & & & 0.660 \\
\hline & $<10$ & 0.712 & 0.947 & 40 & 24 & & 12 & 44 & \\
\hline & $\geq 10$ & & & 6 & 2 & & 1 & 6 & \\
\hline \multirow[t]{3}{*}{ Stage } & & & & & & 0.074 & & & 0.038 \\
\hline & । & $<0.001$ & $<0.001$ & 19 & 17 & & 12 & 23 & \\
\hline & $\|-I V$ & & & 27 & 10 & & 5 & 32 & \\
\hline DFS & & & & 44 & 18 & 0.175 & & & \\
\hline OS & & & & 44 & 18 & 0.012 & & & \\
\hline
\end{tabular}

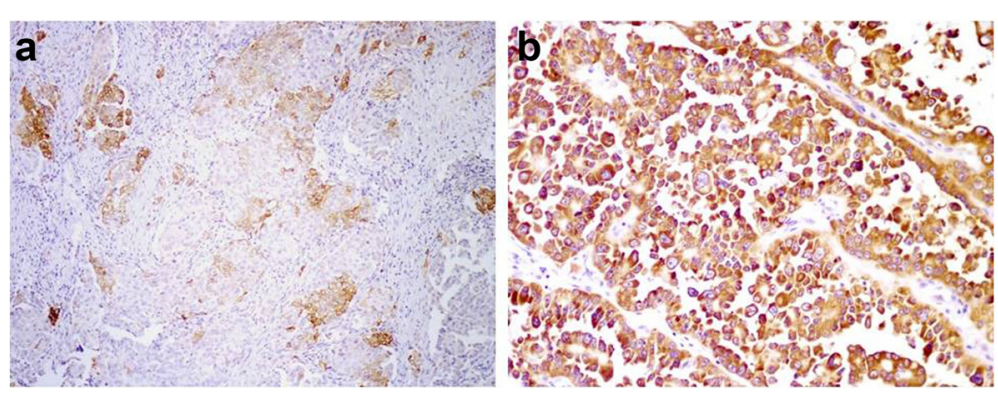

Fig. 2 a Focal and moderately positive staining for IMP3 expression. b Diffuse and strong IMP3-positive staining (original magnification, $\times 200$ ) 

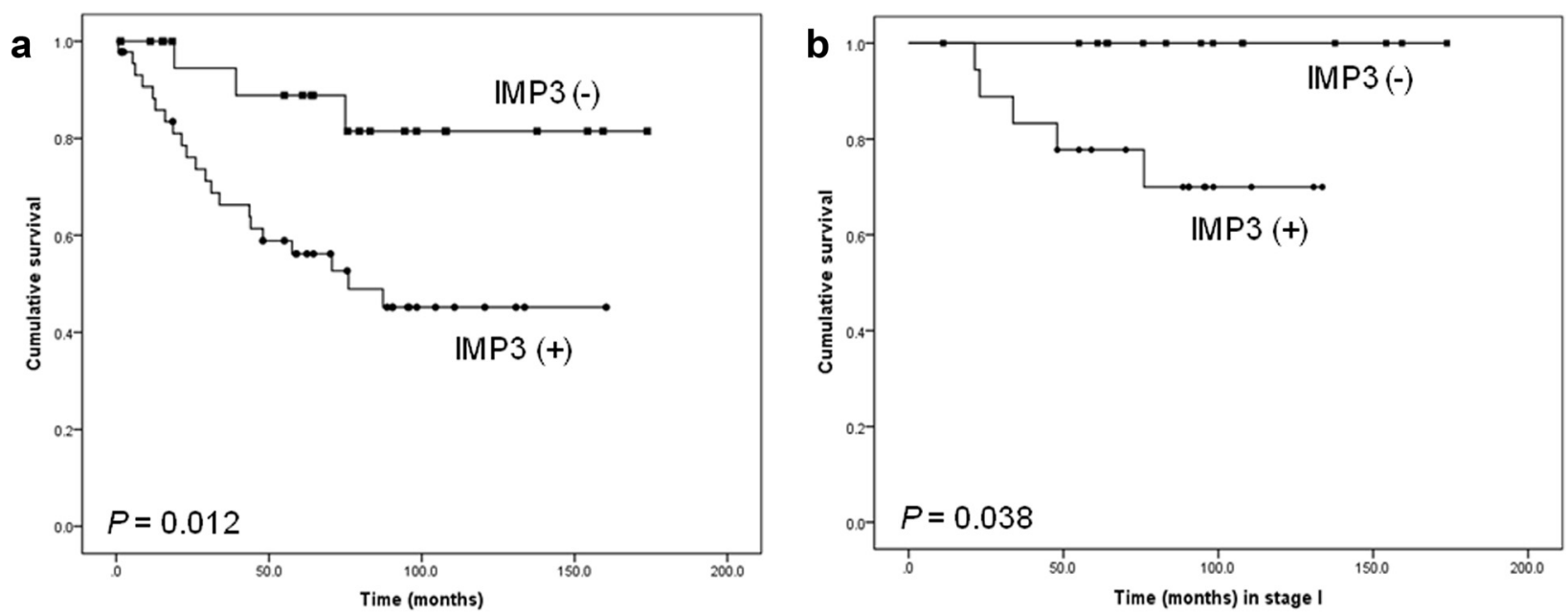

Fig. 3 a The OS of the patients with positive IMP3 expression was worse than that of the negative cases among 73 cases. $\mathbf{b}$ The same trend was observed in 36 cases with stage I disease

(36 of 73), which is similar to the percentages that have been reported in other populations.

According to a report by Higasi et al., the five-year DFS and OS rates of each stage of ovarian CCC were $84 \%$ and $88 \%$ (stage I), $57 \%$ and $70 \%$ (stage II), $25 \%$ and $33 \%$ (stage III), and $0 \%$ and $0 \%$ (stage IV), respectively [27]. The five-year OS rates of the patients in our group were similar to those reported in other studies of non-Chinese populations: $78.8 \%$ (stage I), $45.5 \%$ (stage II), $27.8 \%$ (stage III), and $0 \%$ (stage IV). According to a previous report of a Chinese population, the five-year OS rate of patients with stage I was $66.8 \%$ [25]; the survival rates in the current study were higher than those in previous reports. A study by Hoskins et al. indicated that the prognosis of patients with CCC in stage $\mathrm{Ia} / \mathrm{Ib}$ was more favorable than that of patients in stage Ic [28] and that the prognosis of patients with stage Ic was closer to that of patient with stage II [29]. However, OS and DFS rates did not significantly differ between stages Ia/Ib and Ic in this group; this result was comparable to the report by Hoskins et al.

Ovarian CCC is closely related to endometriosis, which was found in $23.3 \%$ of our cohort. This value is similar to the frequency of $26.8 \%$ reported in another Chinese population [26] but lower than that reported in other countries (approximately $45 \%$ ) [30, 31]. Scarfone et al. reported that patients with $\mathrm{CCC}$ arising from endometriosis are generally younger than those with general CCC [32]. Our results indicate that CCC cases coexisting with endometriosis also had a trend of occurrence among relatively younger patients and were often unilateral, although few cases arose directly from endometriosis. The presence or absence of endometriosis was not related to prognosis in any case in our study or in a previously reported study [32]; however, some studies have observed a better prognosis in CCC-associated endometriosis [33, 34].

Ascites were often observed during operation and were a trend among the patients with an unfavorable prognosis compared to patients without ascites with respect to DFS $(P=0.055)$ but not OS $(P=0.271)$.

The classical morphology of ovarian CCC cases is tubulocystic, solid and papillary or with an admixture of differnt growth pattern [17]. In the present study, $72 \%$ of the cases contained papillary structures. A mixture of clear cells and oxyphilic cells was the most common cell type. The tumor stroma was often observed to be a mixture of hyalinized, myxoid, or fibroblastic types, whereas pure hyalinization or pure myxoid stroma was uncommon. In our cases, the average mitotic index was 4.6/10 HPFs, with most cases being lower than 10/10 HPFs (89 \% of the group), which is quite consistent with previous reports [31]. Furthermore, we did not observe any statistically significant differences in the relationship between morphology and prognosis.

The importance of IMP3 expression in the female reproductive system is controversial. One study suggested that IMP3 was a prognostic marker in metastatic ovarian cancer [35], Kobel et al. suggested that IMP3 expression was an independent indicator of a poor ovarian CCC prognosis [12], and Noske et al. suggested that IMP3 expression was a marker of a good prognosis in ovarian cancer (including serous carcinoma and non-serous carcinoma) [15]. No further reports regarding IMP3 as a prognostic biomarker have been published. The present study demonstrated that IMP3 expression is closely related to an unfavorable prognosis and that it may be used as a potential indicator to estimate poor prognosis. The results of our study are similar to those of Kobel et al. In endometrial clear cell carcinoma, IMP3 was 
reported to be closely correlated with poor prognosis and relapse free survival (RFS) [13].

Furthermore, we analyzed the follow-up data of 33 patients with stage I CCC and found that IMP3 positivity was associated with a shorter OS (76.0 months vs. 96.5 months, $P=0.038$ ). None of the 17 IMP3-negative cases of stage I died, but 4 of 19 IMP3-positive cases died from ovarian CCC metastasis. The results for the 5 -year survival rate in our series show the same trend reported by Kobel et al. Most ovarian CCC patients received adjuvant chemotherapy after surgery. But for those stage I patients, the benefit from chemotherapy was not sufficient $[36,37]$. However, the patients may have, to endure severe side effects of chemotherapy. IMP3, as a potential stratification prognostic factor in stage I cases, may be used to stratify patients whom may benefit from adjuvant therapy. However, IMP3+ tumors in stage I patients still have a wide range of survival (23-133.6 months) in our study. Thus, further research are needed to verify the prognostic significance of IMP3 in ovarian CCC. For example, studies are needed to demonstrate whether IMP3 staining correlates well with molecular tests for IMP3 expression, and furthermore, that IMP3 expression by molecular test correlates with prognosis.

It had been reported that knockdown of IMP3 in cervical cancer, breast cancer and melanoma cell lines could reduce cell migration and invasiveness [38-40]. In renal cell carcinoma, IMP3 can also promote cell migration and invasion by activation of NF- $\mathrm{KB}$ pathway [41]. As recently reported, knockdown of IMP3 decreased cell proliferation, migration, and invasion, and increased the sensitivity to platinum in ovarian cancer through increased expression of hCTR1 [42]. We presume that the overexpression of IMP3 can increase the resistance to platinum, which may lead to poor prognosis in ovarian $\mathrm{CCC}$, but further study is required.

\section{Conclusion}

In conclusion, we demonstrated that tumor stage and IMP3 expression are prognostic indicator in ovarian CCC. IMP3 overexpression is a potential marker of poor prognosis for ovarian CCC, even in stage I. More studies are required to further clarify the mechanism of IMP3 expression and its significance in ovarian CCC.

\section{Competing interests}

The authors declare that they have no competing interest.

\section{Authors' contributions}

RB and WY designed and revised the paper. WZ and XC carried out the immunohistochemical staining. ZF collected the clinical and follow-up information and drafted the paper. RB, XS, YC and WY diagnosed the cases. All authors read and approved the final manuscript.

\section{Acknowledgements}

This work was supported by the key project of Science and Technology Commission of Shanghai Municipality (12411950300) for Xiaohua Wu.

\section{Author details}

'Department of Pathology, Fudan University Shanghai Cancer Center, Shanghai 200032, China. ${ }^{2}$ Department of Oncology, Shanghai Medical College, Fudan University, Shanghai 200032, China. ${ }^{3}$ Psycho-Oncology Research \& Training (CePORT), School of Public Health, The University of Hong Kong, Pok Fu Lam, Hong Kong. ${ }^{4}$ Department of Gynecologic Oncology, Fudan University Shanghai Cancer Center, Shanghai 200032, China.

Received: 12 November 2015 Accepted: 14 January 2016

Published online: 02 February 2016

\section{References}

1. Anglesio MS, Carey MS, Kobel M, Mackay H, Huntsman DG. Clear cell carcinoma of the ovary: a report from the first Ovarian Clear Cell Symposium, June 24th, 2010. Gynecol Oncol. 2011;121:407-15.

2. Han G, Gilks CB, Leung S, Ewanowich CA, Irving JA, Longacre TA, et al. Mixed ovarian epithelial carcinomas with clear cell and serous components are variants of high-grade serous carcinoma: an interobserver correlative and immunohistochemical study of 32 cases. Am J Surg Pathol. 2008;32:955-64.

3. Sugiyama T, Kamura T, Kigawa J, Terakawa N, Kikuchi Y, Kita T, et al. Clinical characteristics of clear cell carcinoma of the ovary: a distinct histologic type with poor prognosis and resistance to platinum-based chemotherapy. Cancer. 2000;88:2584-9.

4. del Carmen MG, Birrer M, Schorge JO. Clear cell carcinoma of the ovary: a review of the literature. Gynecol Oncol. 2012;126:481-90.

5. Lee YY, Kim TJ, Kim MJ, Kim HJ, Song T, Kim MK, et al. Prognosis of ovarian clear cell carcinoma compared to other histological subtypes: a metaanalysis. Gynecol Oncol. 2011;122:541-7.

6. Chan JK, Teoh D, Hu JM, Shin JY, Osann K, Kapp DS. Do clear cell ovarian carcinomas have poorer prognosis compared to other epithelial cell types? A study of 1411 clear cell ovarian cancers. Gynecol Oncol. 2008;109:370-6.

7. Yamamoto S, Tsuda H, Shimazaki H, Takano M, Yoshikawa T, Kuzuya K, et al. Histological grading of ovarian clear cell adenocarcinoma: proposal for a simple and reproducible grouping system based on tumor growth architecture. Int J Gynecol Pathol. 2012;31:116-24.

8. Jeng YM, Wang TH, Lu SH, Yuan RH, Hsu HC. Prognostic significance of insulin-like growth factor II mRNA-binding protein 3 expression in gastric adenocarcinoma. Br J Surg. 2009;96:66-73.

9. Yuan $\mathrm{RH}$, Wang CC, Chou CC, Chang KJ, Lee PH, Jeng YM. Diffuse expression of RNA-binding protein IMP3 predicts high-stage lymph node metastasis and poor prognosis in colorectal adenocarcinoma. Ann Surg Oncol. 2009;16:1711-9.

10. Schaeffer DF, Owen DR, Lim HJ, Buczkowski AK, Chung SW, Scudamore CH, et al. Insulin-like growth factor 2 mRNA binding protein 3 (IGF2BP3) overexpression in pancreatic ductal adenocarcinoma correlates with poor survival. BMC Cancer. 2010;10:59.

11. Jeng YM, Chang CC, Hu FC, Chou HY, Kao HL, Wang TH, et al. RNA-binding protein insulin-like growth factor II mRNA-binding protein 3 expression promotes tumor invasion and predicts early recurrence and poor prognosis in hepatocellular carcinoma. Hepatology. 2008;48:1118-27.

12. Kobel M, Xu H, Bourne PA, Spaulding BO, Shih le M, Mao TL, et al. IGF2BP3 (IMP3) expression is a marker of unfavorable prognosis in ovarian carcinoma of clear cell subtype. Mod Pathol. 2009;22:469-75.

13. Fadare O, Liang SX, Crispens MA, Jones 3rd HW, Khabele D, Gwin K, et al. Expression of the oncofetal protein IGF2BP3 in endometrial clear cell carcinoma: assessment of frequency and significance. Hum Pathol. 2013:44:1508-15.

14. Wei Q, Yan J, Fu B, Liu J, Zhong L, Yang Q, et al. IMP3 expression is associated with poor survival in cervical squamous cell carcinoma. Hum Pathol. 2014:45:2218-24.

15. Noske A, Faggad A, Wirtz R, Darb-Esfahani S, Sehouli J, Sinn B, et al. IMP3 expression in human ovarian cancer is associated with improved survival. Int J Gynecol Pathol. 2009;28:203-10.

16. Mutch DG, Prat J. 2014 FIGO staging for ovarian, fallopian tube and peritoneal cancer. Gynecol Oncol. 2014;133:401-4. 
17. DeLair D, Oliva E, Kobel M, Macias A, Gilks CB, Soslow RA. Morphologic spectrum of immunohistochemically characterized clear cell carcinoma of the ovary: a study of 155 cases. Am J Surg Pathol. 2011;35:36-44.

18. Walter O, Prasad M, Lu S, Quinlan RM, Edmiston KL, Khan A. IMP3 is a novel biomarker for triple negative invasive mammary carcinoma associated with a more aggressive phenotype. Hum Pathol. 2009:40:1528-33.

19. Therasse P, Arbuck SG, Eisenhauer EA, Wanders J, Kaplan RS, Rubinstein L, et al. New guidelines to evaluate the response to treatment in solid tumors. European Organization for Research and Treatment of Cancer, National Cancer Institute of the United States, National Cancer Institute of Canada. J Natl Cancer Inst. 2000;92:205-16.

20. Behbakht K, Randall TC, Benjamin I, Morgan MA, King S, Rubin SC. Clinical characteristics of clear cell carcinoma of the ovary. Gynecol Oncol. 1998;70:255-8.

21. Pather S, Quinn MA. Clear-cell cancer of the ovary-is it chemosensitive? Int J Gynecol Cancer. 2005:15:432-7.

22. Takano M, Kikuchi Y, Yaegashi N, Kuzuya K, Ueki M, Tsuda H, et al. Clear cell carcinoma of the ovary: a retrospective multicentre experience of 254 patients with complete surgical staging. Br J Cancer. 2006;94:1369-74.

23. Jenison EL, Montag AG, Griffiths CT, Welch WR, Lavin PT, Greer J, et al. Clear cell adenocarcinoma of the ovary: a clinical analysis and comparison with serous carcinoma. Gynecol Oncol. 1989:32:65-71.

24. Kobel M, Kalloger SE, Huntsman DG, Santos JL, Swenerton KD, Seidman JD, et al. Differences in tumor type in low-stage versus high-stage ovarian carcinomas. Int J Gynecol Pathol. 2010;29:203-11.

25. Ma SK, Zhang HT, Wu LY, Liu LY. Prognostic analysis of 88 patients with ovarian clear cell carcinoma. Zhonghua Zhong Liu Za Zhi. 2007;29:784-8.

26. Ye S, You Y, Yang J, Cao D, Bai H, Huang H, et al. Comparison of pure and mixed-type clear cell carcinoma of the ovary: a clinicopathological analysis of 341 Chinese patients. Int J Gynecol Cancer. 2014;24:1590-6.

27. Higashi M, Kajiyama H, Shibata K, Mizuno M, Mizuno K, Hosono S, et al. Survival impact of capsule rupture in stage I clear cell carcinoma of the ovary in comparison with other histological types. Gynecol Oncol. 2011;123:474-8.

28. Mizuno M, Kikkawa F, Shibata K, Kajiyama H, Suzuki T, Ino K, et al. Long-term prognosis of stage I ovarian carcinoma. Prognostic importance of intraoperative rupture. Oncology. 2003;65:29-36.

29. Hoskins PJ, Le N, Gilks B, Tinker A, Santos J, Wong F, et al. Low-stage ovarian clear cell carcinoma: population-based outcomes in British Columbia, Canada, with evidence for a survival benefit as a result of irradiation. J Clin Oncol. 2012;30:1656-62.

30. Rauh-Hain JA, Winograd D, Growdon WB, Schorge JO, Goodman AK Boruta DM, et al. Prognostic determinants in patients with uterine and ovarian clear carcinoma. Gynecol Oncol. 2012;125:376-80.

31. Bennett JA, Dong F, Young RH, Oliva E. Clear cell carcinomas of the ovary. Evaluation of prognostic parameters based on a clinicopathologic analysis of 100 cases. Histopathology. 2015;66:808-15.

32. Scarfone G, Bergamini A, Noli S, Villa A, Cipriani S, Taccagni G, et al. Characteristics of clear cell ovarian cancer arising from endometriosis: a two center cohort study. Gynecol Oncol. 2014;133:480-4.

33. Davis M, Rauh-Hain JA, Andrade C, Boruta 2nd DM, Schorge JO, Horowitz NS, et al. Comparison of clinical outcomes of patients with clear cell and endometrioid ovarian cancer associated with endometriosis to papillary serous carcinoma of the ovary. Gynecol Oncol. 2014;132:760-6.

34. Orezzoli JP, Russell AH, Oliva E, Del Carmen MG, Eichhorn J, Fuller AF. Prognostic implication of endometriosis in clear cell carcinoma of the ovary. Gynecol Oncol. 2008;110:336-44.

35. Slipicevic A, Oy GF, Askildt IC, Holth A, Hellesylt E, Florenes VA, et al. Diagnostic and prognostic role of the insulin growth factor pathway members insulin-like growth factor-II and insulin-like growth factor binding protein-3 in serous effusions. Hum Pathol. 2009;40:527-37.

36. Takada T, Iwase H, litsuka C, Nomura H, Sakamoto K, Omatsu K, et al. Adjuvant chemotherapy for stage I clear cell carcinoma of the ovary: an analysis of fully staged patients. Int J Gynecol Cancer. 2012;22:573-8.

37. Mizuno M, Kajiyama H, Shibata K, Mizuno K, Yamamuro O, Kawai M, et al. Adjuvant chemotherapy for stage i ovarian clear cell carcinoma: is it necessary for stage IA? Int J Gynecol Cancer. 2012;22:1143-9.

38. Lu D, Yang $X$, Jiang NY, Woda BA, Liu Q, Dresser $K$, et al. IMP3, a new biomarker to predict progression of cervical intraepithelial neoplasia into invasive cancer. Am J Surg Pathol. 2011;35:1638-45.

39. Samanta S, Sharma VM, Khan A, Mercurio AM. Regulation of IMP3 by EGFR signaling and repression by ERbeta: implications for triple-negative breast cancer. Oncogene. 2012;31:4689-97.
40. Kabbarah O, Nogueira C, Feng B, Nazarian RM, Bosenberg M, Wu M, et al. Integrative genome comparison of primary and metastatic melanomas. PLoS One. 2010;5:e10770.

41. Pei X, Li M, Zhan J, Yu Y, Wei X, Guan L, et al. Enhanced IMP3 Expression Activates NF-kB Pathway and Promotes Renal Cell Carcinoma Progression. PLoS One. 2015;10:e0124338.

42. Hsu KF, Shen MR, Huang YF, Cheng YM, Lin SH, Chow NH, et al. Overexpression of the RNA-binding proteins Lin28B and IGF2BP3 (IMP3) is associated with chemoresistance and poor disease outcome in ovarian cancer. Br J Cancer. 2015;113:414-24.

\section{Submit your next manuscript to BioMed Central and we will help you at every step:}

- We accept pre-submission inquiries

- Our selector tool helps you to find the most relevant journal

- We provide round the clock customer support

- Convenient online submission

- Thorough peer review

- Inclusion in PubMed and all major indexing services

- Maximum visibility for your research

Submit your manuscript at www.biomedcentral.com/submit
) Biomed Central 